volved. Some patients may have spent time in an intensive treatment unit or in a medical ward before transfer, but $75 \%$ are discharged within $48 \mathrm{~h}$ of admission to the unit, approximately $15 \%$ to psychiatric hospitals.

Outpatient follow-up is now carried out in the unit, which has reduced the default rate to less than $5 \%$, and over the past three years the relapse rate, defined as repeat of selfpoisoning within 12 months, has fallen to less than $10 \%$.

JOY WeST

St Helier Hospital,

Carshalton, Surrey

Barraclough, B, et al, British fournal of Psychiatry, 1974, 125, 355.

\section{Treatment of chlonorchiasis}

SIR,-Your timely leading article on liver fluke infection (29 April, p 1091) draws attention to the problem of infection with Clonorchis sinensis in countries like Britain and Canada, which have appreciable numbers of Chinese immigrants, but makes no reference to a recent investigation in New York City in which a single stool examination from each of 150 Chinese-born residents showed that $26^{\circ} \%$ were infected with this liver fluke. ${ }^{1}$ Subsequent correspondence with the senior author of this report has revealed that no effective treatment is available for these patients in the USA.

In a letter in $1975^{\circ}$ I reported that excellent results had been obtained at the Hospital for Tropical Diseases in London using a supply of hexachloroparaxylol (HPX) which I had obtained from a colleague in China (where the drug is freely available) and at the same time I drew attention to the fact that this drug was unobtainable in the West. Since then appeals to Hoechst Pharmaceuticals to remarket their product (Hetol) have failed and I have been equally unsuccessful in persuading a leading British pharmaceutical company to approve the manufacture of HPX, even though the company's research department found the drug to be non-toxic to laboratory animals. Since the publication of that letter I have corresponded with physicians in Britain, Canada, the United States, Switzerland, West Germany, and even Hong Kong, all complaining of inability of any alternative drug of value in treating clonorchiasis. At this very moment I know of a proved case in London urgently in need of treatment. Is there no pharmaceutical company in Britain willing to meet this challenge and is the NHS prepared to let this problem go by default?

W H JOPLING

London SW 16

1 Kammerer, W S, et al, Tropical Doctor, 1977, 7, 105.

2 Jopling, W H, British Medical fournal, 1975, 3, 767.

\section{Prognostic value of oculovestibular reflex}

SIR,-In their interesting paper $\operatorname{Dr} M A$ Hanid and others (22 April, p 1029) emphasise the importance of observing oculovestibular responses (OVR) in patients in hepatic coma. They conclude that "the prognostic value of the OVR in fulminant hepatic failure was absolute." Our own coma study ${ }^{1-3}$ to which they refer has now been extended to include 500 patients and our experience of the behaviour of OVRs in hepatic coma differs somewhat from that of Dr Hanid and his colleagues. Of 51 patients in hepatic coma, 19 fulfilled the criteria of fulminant hepatic coma. Of the whole group only four patients had absent OVRs at the time of initial assessment and one of these recovered from coma.

There are a number of possible reasons for our differing results. We accept an OVR as negative only if there is no response after injection of $100 \mathrm{ml}$ of ice-cold water into the auditory canal. Secondly, the effect of drugs other than paralytic agents must be considered in evaluation of the OVR, particularly in patients with hepatic disease, in whom the metabolism of drugs may be retarded. However, the main discrepancy between our results must depend on our differing interpretations of the word prognosis.

Our observations on OVRs were made with a view to evaluating this sign as a predictor of final outcome. Dr Hanid and his colleagues appear to have monitored the OVR in the course of the illness and they observed its disappearance as deterioration progressed. All dying patients at some stage will lose the OVR and we would submit that as an early predictor of outcome in hepatic coma these responses are of less value than they imply.

\section{N E F Cartlidge} David Bates

Department of Neurology,

Royal Victoria Infirmary
Newcastle upon Tyne

Department of Medicine,

ROBIN KNILL JONES

Caronna, J J, et al, Transactions of the American Neurological Association, 1975, 100, 25.

${ }^{3}$ Bates, D, et al, Annals of Neurology, 1977, 2, 211.

SIR,-Dr M A Hanid and others in their recent article (22 April, $p$ 1029) stress what they call the absolute prognostic value of the oculovestibular reflex in fulminant hepatic failure. By this they imply that the absence of any movement of the eyes in response to irrigation of either ear with iced water implies an inevitably fatal outcome. They go on to generalise their argument by quoting a similar totally adverse prognostic implication in head injuries $^{1}$ and in medical (including other metabolic) causes of coma. ${ }^{2}$ In a recent study ${ }^{3}$ of coma in childhood Seshia et al came to an identical conclusion: of 75 children, all four who had absent ocular motility using ice caloric testing died irrespective of the presence of other signs of brainstem function.

Any exceptions to "absolute" rules must be recognised, especially when the question is one of life or death. We therefore briefly report a single case ${ }^{4}$ of very severe diabetic coma in which total neurological recovery followed earlier complete absence of oculovestibular reflexes.

A 12!-year-old girl with a seven-day history of thirst was found unconscious in bed on the morning of 2 November 1975 and admitted to the intensive therapy unit of this hospital. She was in shock with unrecordable blood pressure, temperature $39.0 \mathrm{C}$, in grade IV coma with no responses except sluggish pupil light reactions, but had shallow respirations with a fruity odour. After rapid infusion of isotonic saline the peripheral circulation improved, blood pressure came within normal limits, and core temperature fell to normal. At this stage the diagnosis of hyperosmolar diahetic coma had been confirmed (blood glucose $180 \mu \mathrm{mol} / 1$ $(3240 \mathrm{mg} 100 \mathrm{ml}$ ), plasma osmolality $430 \mathrm{mmol} \mathrm{kg}$, $\mathrm{pH} 7.02$ ) and the neurological examination was repeated in full..$^{5}$ All neurological reactivity was absent apart from some pupil light reaction, intact oculocardiac reflex and spontanecus regular respiration. In particular, irrigation of either ear with large quantities of iced water induced no ocular movements and doll's eye responses wer absent. On this basis she was regarded as having a pure metabolic coma, and treated with $6 \mathrm{U}$ of soluble insulin intravenously and intramuscularly and then $4 \mathrm{U}$ intramuscularly hourly. Within $3 \mathrm{~h}$ she gained some tonic ocular deviation on ice calorie testing, and she was obeying commands by $48 \mathrm{~h}$. Extensive dependent ischaemic skin lesions which may have reflected her extreme hyperglycaemia ${ }^{4}$ healed with scarring, but she made a complete neurological and psychological recovery (Wechsler testing on 23 February 1976: verbal scale 118, performance 111, full scale IQ 115.)

Your readers will be well aware that poisoning can abolish all neurological reactivity. It is vital to remember that severe brainstem dysfunction may also occur in metabolic coma and that it should be entirely reversible if structural damage from brain swelling can be prevented by meticulous therapy.

It is a pleasure to thank Dr Oman Craig for permission to report this case.

J B P STEPHENSON K Evelyn Byrne

Royal Hospital for Sick Children,

Glasgow

Poulsen, J, and Zilstorff, K, Acta Neurologica Scandinavica, 1972, $\mathbf{4 8}, 282$. Neurological Association, 1975, 100, the American Seshia, S S, Seshia, M M K, and Sachdeva, R K.
Developmental Medicine and Child Neurology, 1977, 19, 614.

Craig, O, Childhood Diabetes and Its Manag
p 221 and fig 32. London, Butterworth, 1977 .

Plum, F, and Posner, J B, The Diagnosis of Stupor and Coma, 2nd edn. Philadelphia, Davis.

\section{Confidentiality of medical records}

SIR,-In their paper on self-poisoning in Nottingham (22 April, p 1032) Dr D R Blake and Professor J R A Mitchell state that "the casualty department staff keep their records on a triplicate form, the third copy of which is processed by the Trent Regional Health Authority in Sheffield for research purposes."

This quotation prompts the question whether the second and third copies include the patient's names and addresses. If they do, other questions arise: (1) Who keeps the second copies? (2) Are the patients warned (for instance, by a large notice in the casualty department) that information about their visit to that department will be sent to the regional health authority? (3) Does this procedure happen in other regions? (4) If so, should I, as an employee of the North-west Thames Region, make sure that I take my overdose in another region, lest my employer regard me as a mental health risk? And since three of the Thames regions have their offices in the same building, will I even be safe in, for example, the North-east Thames Region?

\section{P TReves Brown}

Radlett, Herts

\section{Price of survival in childhood leukaemia}

SIR,-We were interested in your leading article (11 February, p 321) and the letter from Dr P G F Swift and others (15 April, p 986) on the price of survival in childhood leukaemia. The initial endocrine study by our group' showed impaired growth hormone (GH) responses to hypoglycaemia in leukaemic children with acute lymphoblastic leukaemia (ALL) several years after they had received cranial irradiation (DXT) with a dose of 2500 
rads in 10 fractions over $2 \frac{1}{2}$ weeks. One of these subjects, who had the same dose of cranial DXT, was clinically GH-deficient and has since grown significantly in response to $\mathrm{GH}$ therapy. Despite the biochemical evidence of impaired GH secretion, in a more recent study $^{2}$ the children receiving this dose of cranial DXT had high-normal somatomedin activities, no significant degree of bone age retardation, and a normal growth rate. Other workers $^{3}$ have suggested that the majority of children with ALL in clinical remission and off all chemotherapy show a normal growth pattern. However, dynamic tests of GH secretion have produced conflicting results with both normal ${ }^{45}$ and abnormal GH responses $^{16}$ reported. This discrepancy was almost certainly due to the variation in the effective biological dose of irradiation reaching the hypothalamic-pituitary axis. Clearly the method of DXT, total dose, number of fractions, fraction size, and duration of DXT will influence the effective biological dose. Thus, although clinical GH deficiency appears to be rare in the Manchester and Bristol centres following cranial DXT for ALL, it may be more common in other centres in the world. Whatever the incidence of clinical $\mathrm{GH}$ deficiency in different centres, we agree that dynamic tests of GH secretion should be performed only when there is evidence of a significant impairment of growth.

Finally, clinical GH deficiency due to radiation-induced damage to the hypothalamic-pituitary axis following treatment of brain tumours has been described with doses as low as 2500 rads $^{7}$ and 3860 rads. ${ }^{8}$ Thus the high dose (5000-6000 rads) suggested by Dr Swift and his colleagues is not mandatory for this complication.

$S M$ SHALET C G BEARDWELL P H MORRIS JONES DOROTHY PEARSON

Christie Hospital and Holt Radium Institute, Manchester

Shalet, S M, et al, Archives of Disease in Childhood, 1976, 51, 489 .

Shalet, S M, et al. Submitted for publication.

Verzosa, M S, et al, International fournal of Radiation Oncology, Biology, and Physics, 1976, 1, 209.

Swift, P G F, et al, Archives of Disease in Childhood. In press.

1976, 31, 463.
.

Schiliro, G, et al, Lancet, 1976, 2, 1031

Perry-Keene, D A, et al, Clinical Endocrinology, 1976, 5, 373. Richards, G E, et al, fournal of Pediatrics, 1976, 89,
553.

\section{Pneumonia}

SIR,-In an article on the treatment of pneumonia (25 March, p 771) I advised that a 12-ml sample of blood should be taken for culture, white cell count, and virus studies. Dr D Craddock (22 April, p 1054) complains that this is "a counsel of perfection which is unlikely to be carried out routinely in many hospitals, let alone in general practice, where few doctors carry syringes larger than $10 \mathrm{ml}$." I readily accept that none of us achieves perfection, but it would surely be wrong to do otherwise than counsel it? So far as syringe size is concerned, $12 \mathrm{ml}$ of blood is easily contained in most standard " $10-\mathrm{ml}$ " syringes and in any case the exact amount is not critical.

Dr Craddock is worried that bacteriologists may not be pleased to receive all these specimens from every case of pneumonia in their catchment area. The bacteriologist would of course receive only the specimens for culture and, if Dr Craddock's local bacteriologist is anything like ours, his complaint will be about the many samples which have to be sent after antibiotics have failed rather than the few which should have been sent before antibiotics were given. I agree that transfer to hospital if fever persists more than four or five days may be unnecessary in viral pneumonia, but I would not be happy about making such a diagnosis with the limited laboratory and radiographic information apparently available to Dr Craddock.

I am further taken to task by Dr Craddock for advising (as recommended in MIMS) that amoxycillin should be given thrice daily rather than eight-hourly. He rightly points out that $15 \mathrm{~h}$ may elapse between the "teatime dose" and the "breakfast dose," but I am surprised that Dr Craddock should relate treatment to such variable feasts as these. As an ex-Liverpudlian he will know that teatime in these parts may be several hours later than in Surrey-and I am told that their breakfast may sometimes coincide with our lunch. At the other extreme the rigid eighthourly antibiotic regimen which he favours could well disrupt the sleep so vital for a patient with pneumonia. Thrice daily dosage -as evenly distributed over the 24 hours as the patient's comfort and convenience may dictate-is surely preferable to either of the alternatives mentioned by Dr Craddock.

Colin M Ogilvie

Broadgreen Hospital,

Liverpool

Poisoning with alkylmercury compounds

SIR,-Your leading article on this subject (11 March, p 599) and the article by Professor L Amin-Zaki and others on methylmercury poisoning in Iraqi children ( $p$ 613) prompt me to make a few comments and to add some personal data.

I had the opportunity to follow up three patients with mild occupational alkylmercury poisoning and to carry out some investigations on men with longterm exposure to organic mercury. The concentrations of methylmercury and ethylmercury in the air of working places frequently and appreciably exceeded the maximum allowable concentration $\left(0.005 \mathrm{mg} / \mathrm{m}^{3}\right)$. The duration in occupation varied between six and eight years. At the time when these patients were examined they had not been exposed for two to six months and their urinary excretion of mercury varied between 1.7 and 2.4 $\mu \mathrm{mol} / 1$ (340 and $480 \mu \mathrm{g} / \mathrm{l}$ ). All complained of asthenia, irascibility, headache, loss of memory, insomnia, paraesthesiae, libido decrease, and impotence. They did not complain of visual troubles but on examination all patients showed a constriction of the visual fields, especially for some colours. No abnormality was found in dark adaptation or in audiometry tests. Mild tremor (handwriting test, alterations in drawing), accentuated in two subjects by intentional movements, hyperreflexia, and decreased temperature and pain sensitivity suggesting sensitive peripheral neuropathy, as well as mild ataxia (finger-nose test) were detected. Semen analyses showed hypospermia in all patients and a considerable increase in the number of abnormal forms in the ejaculate (teratospermia). After two years the same neurological and physiological symptoms and signs wer present and in almost all cases were no less severe. This evolution supports the view of Professor Amin-Zaki and his colleagues that poisoning due to long-term absorption has a different evolution and prognosis from subacute poisoning (for example, cases reported in Pakistan and Iraq, in which recovery was more rapid).

A group of 50 men chronically exposed to increased concentrations of organic mercury (mean duration in occupation 10.5 years) were examined. Signs of poisoning were not found but an increased incidence of sexual troubles and decrease of libido were recorded. In 28 volunteers in whom other causes of insufficiency of the germinal epithelium were ruled out the incidence of hypospermia, asthenospermia (decrease in percentage of motile spermatozoa during the first three hours after ejaculation), and teratospermia was significantly higher than in an equal number of controls of similar age. The severity of teratospermia was higher in men with increased absorption of the mercury (urinary excretion in the range 1.5-4.4 $\mu \mathrm{mol} / 1$ (300-890 $\mu \mathrm{g} / \mathrm{l})$ than in those without increased absorption at the time of examination (less than $300 \mu \mathrm{g} / \mathrm{l}){ }^{1}$

In 18 exposed men (urinary excretion in the range $0 \cdot 5-2 \cdot 1 \mu \mathrm{mol} / 1(100-420 \mu \mathrm{g} / \mathrm{l}))$ in whom short-term cultures $(52 \mathrm{~h}$, Evans's modified method) of peripheral lymphocytes were carried out, an increased incidence of chromatid breaks (though not significantly different from controls) and chromosome acentric fragments (significant difference, $\mathrm{P}<0.001$ ) was noticed. ${ }^{2}$

It would be of interest if at least chromosome studies on peripheral lymphocytes could be carried out in the future in the poisoned children, and possibly long-term fertility studies.

I thank Dr Ioana Lancranian for the endocrine examination of the subjects as well as for an important contribution to semen examinations, and Dr Luminita Negru for help in lymphocyte culture and examinations.

HORIA I POPESCU

Laboratory of Nuclear Medicine
Department of Research and

Development,

Solco Basle AG,
Birsfelden, Switzerland

'Lancranian, I, et al, in Symposium on the Influence of
Some Biological and Environmental Factors in
Human Reproduction, Bucharest, 1974, May 14-15.
' Popescu, H I, and L Negru, in Second International
Symposium on Chromosome Aberrations by Industrial
Chemicals and Vinyl Chloride Toxicity, Milan,
October 28-29, 1974.

\section{Whooping cough}

SIR,-In your leading article on this topic (22 April, p 1007) it is suggested that cephaloridine may be especially useful in treating secondary bacterial infection which may occur in this disease and can result in fatal pneumonia. Cephaloridine is likely to be effective in pneumococcal or staphylococcal infection but is unlikely to be effective in haemophilus infections. For this latter reason it would seem to be an unwise choice and certainly should not be recommended in a leading article.

Department of Laboratory Medicine,
Ruchill Hospital,

R J FALLON

Glasgow

SIR,-I read Dr D T D Hughes' paper (6 May, $p$ 1202) on the use of cough suppressants etc with great interest and his summing up of the use of these drugs was excellent.

I must, however, take issue with him about the suppression of cough in whooping cough when it produces vomiting. The very act of vomiting in a child with tenacious sputum, as is the case in whooping cough, is the best way of clearing the bronchial tree. This is borne out by the age-old clinical observation that after vomiting the child will often be free of cough for a sufficiently long time for it to absorb some nutriment. Furthermore, the act 